\title{
Experiência mobile in store: um panorama do mercado atual
}

Considerando a importância de se pesquisar acerca de tecnologias móveis, o presente artigo tem como objetivo investigar como se dá a experiência mobile in store em lojas de um shopping center. A coleta de dados se deu no maior shopping da cidade de João Pessoa/PB, utilizou-se um roteiro de pesquisa estruturado para conduzir a observação participante realizada em trinta e duas empresas. Após coletados, os dados foram analisados por meio de uma análise interpretativadescritiva e confrontados com a teoria, para tanto criou-se as categorias de observação: Uso de tecnologias mobile, Capacitação dos colaboradores, Ambiente da loja, Relacionamento com o cliente e Canais de venda. A partir das análises, observou-se que a adoção de tecnologias mobile pelas empresas analisadas ainda é mínima, de modo que não são realizados esforços em torno da capacitação dos colaboradores, adequações no ambiente da loja, estratégias de relacionamento com o cliente e canais de venda. Tal fato permite concluir que a experiência mobile em lojas de um shopping de João Pessoa é incipiente, de modo que poderiam ser adotadas tecnologias, mesmo as mais básicas como a disponibilidade de internet móvel para que as lojas se adequassem à essa crescente dinâmica de consumo.

Palavras-chave: Tecnologias mobile; Experiência mobile; Consumo online.

\section{Mobile in store experience: a current market overview}

Considering the importance of researching about mobile technologies, this article aims to investigate how the mobile in store experience occurs in stores in a shopping center. Data collection took place in the largest mall in the city of João Pessoa/PB, a structured research script was used to conduct participant observation carried out in thirty-two companies. After being collected, the data were analyzed by means of an interpretative-descriptive analysis and compared with the theory, for this purpose the categories of observation were created: Use of mobile technologies, Employee training, Store environment, Customer relationship and Channels of sales. From the analysis, it was observed that the adoption of mobile technologies by the companies analyzed is still minimal, so that no efforts are made around the training of employees, adaptations in the store environment, customer relationship strategies and communication channels. sale. This fact allows us to conclude that the mobile experience in stores in a shopping center in João Pessoa is incipient, so that technologies, even the most basic ones, such as the availability of mobile internet, could be adopted so that stores can adapt to this growing consumption dynamics.

Keywords: Mobile technologies; Mobile experience; Online consumption.

Topic: Marketing e Estratégias Mercadológicas

Reviewed anonymously in the process of blind peer.
Received: $15 / 03 / 2020$

Approved: 02/04/2020
Bruna Cordeiro de Sousa (iD

Universidade Federal da Paraíba, Brasil

http://lattes.cnpq.br/9303708406333469

http://orcid.org/0000-0003-4983-085X

brunacsadm@gmail.com

Rebeca Formiga Figueira (iD

Universidade Federal da Paraíba, Brasil

http://lattes.cnpq.br/4442875658950607

http://orcid.org/0000-0002-7979-9411

rebecaformiga@gmail.com

Dayane Renaly Lopes de Oliveira (it)

Universidade Federal da Paraíba, Brasil

http://lattes.cnpq.br/5381172592972403

http://orcid.org/0000-0002-2406-2762

dayanee.reenaly@gmail.com

\author{
Bruna Lourena de Lima Dantas (iD \\ Universidade Federal da Paraíba, Brasil \\ http://lattes.cnpq.br/2008743465694884 \\ http://orcid.org/0000-0002-3935-5947 \\ brunalimadantas.adm@gmail.com \\ Renata Francisco Baldanza (iD \\ Universidade Federal da Paraíba, Brasil \\ http://lattes.cnpq.br/4146825134309350 \\ http://orcid.org/0000-0002-6157-6922 \\ renatabaldanza@gmail.com
}

Referencing this:

SOUSA, B. C.; FIGUEIRA, R. F.; OLIVEIRA, D. R. L.; DANTAS, B. L. L.; BALDANZA, R. F.. Experiência mobile in store: um panorama do mercado atual. Revista Brasileira de Administração Científica, v.11, n.2, p.42-65, 2020. DOI: http://doi.org/10.6008/CBPC2179$\underline{684 X .2020 .002 .0004}$ 


\section{INTRODUÇÃO}

Estudos sobre o M-Commerce (Comércio Móvel) atraem o interesse de especialistas em comércio eletrônico e de lojas físicas de varejo desde que os dispositivos móveis e portáteis se tornaram um meio amplo e eficaz de transações comerciais e práticas de negócios (KOUROUTHANASSIS et al., 2012). No Brasil, por exemplo, o número de pessoas com celular cresceu mais de 131\% entre os anos de 2005 e 2013, segundo dados da Pesquisa Nacional por Amostra de Domicílios - PNAD (2013) sobre as Tecnologias de Informação e Comunicação, divulgado pelo Instituto Brasileiro de Geografia e Estatística (IBGE). Acrescido a isto, a popularidade do comércio móvel vem aumentando cada vez mais à medida que os smartphones se proliferaram e as redes de dados móveis de alta velocidade se tornaram cada vez mais onipresentes nos últimos anos (ZHANG et al., 2015).

Em 2016, uma pesquisa realizada pelo PNAD revelou que 116 milhões de brasileiros se conectaram a internet durante aquele ano, sendo que a maioria usou smartphones para navegar. Em pesquisa recente, o IBGE (2018) informou que o número de usuários de smartphone cresceu ainda mais, alcançando o número de 138 milhões de brasileiros. Devido a este avanço, às atividades de consumo e ao fácil acesso aos smartphones pelos consumidores, surge o conceito de Marketing Móvel. Esse envolve a comunicação bidirecional ou multidirecional e promoção de uma oferta entre uma empresa e seus clientes usando o celular, um termo que se refere ao meio móvel, dispositivo, canal ou tecnologia e que está crescendo em importância no varejo (SHANKAR et al., 2010).

De acordo com Shankar et al. (2016), o marketing móvel tem o potencial de mudar o paradigma do varejo, passando de um marketing baseado nos consumidores que entram no ambiente de varejo para os varejistas que entram no ambiente do consumidor por meio de dispositivos móveis a qualquer hora e em qualquer lugar. Sabe-se que as informações dos produtos e serviços dadas em situações de compra influenciam o comportamento de compra. Na perspectiva do Mobile in Store não é diferente. Quanto mais informações, facilidade na compra e experiência positiva na loja física, mais os consumidores estão propensos a consumir.

A tomada de decisão do consumidor é um ponto crucial no Ponto de Venda (PDV), por isso, é importante que as empresas entendam e deem o suporte necessário para os consumidores "em movimento", isto é, quando eles estão realmente dentro de uma loja de varejo. Logo, fica fácil entender que as empresas precisam desenvolver estratégias de marketing que forneçam um ambiente de loja favorável e atrativo auxiliando no apoio à decisão dos consumidores a partir do contexto atual do Mobile in Store (VAN DER HEIJDEN, 2006).

Corroborando com este pensamento, na visão de Kowatsch et al. (2010), o uso de Agentes de Recomendação Móvel (MRAs); tais como: Internet Wi-fi, aplicativos, QR-Code nos produtos, Website, experiência a partir da realidade aumentada e virtual dentre outros; aumenta de maneira considerável o valor percebido das informações do produto/serviço na visão dos usuários (consumidores), e isto facilita e promove o consumo, além de gerar uma experiência positiva dos clientes na loja. Com isso, a utilidade 
percebida influencia as compras de produtos, prevê intenções de uso e armazena as preferências dos consumidores.

Assim, pode-se dizer que o uso de MRAs de forma efetiva satisfaz tanto as necessidades de informação dos consumidores quanto as necessidades de comunicação dos varejistas. Isto promove novos modelos de negócios (estratégias) para as lojas de varejo que devem ser considerados para aprimorar a experiência de consumo de seus clientes.

À luz do exposto, a abordagem proposta nesta pesquisa ocupou-se em analisar a experiência mobile in store em lojas de pequeno (Satélite) e grandes portes (Âncora) de um shopping center localizado na cidade de João Pessoa - Paraíba. Para tanto, por meio de um roteiro estruturado e de observação participante, as autoras descrevem um panorama geral do mercado atual quanto ao uso de tecnologias móveis e a experiência no Ponto de Venda (PDV) dos consumidores. Diante desse contexto, pretende-se investigar: Como se dá a experiência mobile in store em lojas de um shopping center?.

\section{REVISÃO TEÓRICA}

\section{Tecnologias digitais e mobile}

É inquestionável a presença e o avanço da tecnologia atualmente. Nota-se a evolução constante nas formas de comunicação, consumo, informação, relacionamento, produção, entre outros. Carvalho (1997) comenta que, a partir da Revolução Industrial, os conhecimentos tecnológicos e a estrutura social foram modificados de forma acelerada. Porém, foi a partir da segunda metade do século XX que a humanidade mais acumulou conhecimentos e acelerou o processo de transformações tecnológicas.

Por muito tempo, a velocidade de propagação de conhecimentos e informações, bem como a troca de experiências entre indivíduos eram demasiadamente lentas. No entanto, com o passar dos anos, a tecnologia alcançou patamares elevados, trazendo maior agilidade e desenvolvimento em vários âmbitos. De acordo com Souza (2014), o conceito de inovação tecnológica se aplica ao sistema de produção de máquinas inteligentes e automatizadas capazes de desempenhar diversas funções.

As expressivas transformações na indústria, na tecnologia e no trabalho propiciaram amplas repercussões sobre o conjunto das relações sociais (FRIDMAN, 2000). Assim, a modernidade cerca-se de mudanças em diferentes âmbitos, quais sejam, tecnológicas, intelectuais, sociais e políticas - que originaram e caracterizaram a sociedade moderna em suas diferentes fases (KUMAR, 1997).

De acordo com Castells (1999) o processo contemporâneo de transformação tecnológica expandese exponencialmente em razão de sua capacidade de criar uma interface entre campos tecnológicos mediante uma linguagem digital comum na qual a informação é gerada, armazenada, recuperada, processada e transmitida.

O desenvolvimento da computação móvel e de tecnologias como internet sem fio, laptops, smartphones e tablets levou as sociedades a um processo de conexão cada vez mais generalizada, de maneira que estar conectado passou a ser um fator preponderante do cotidiano (LIMA et al., 2013). As tecnologias 
digitais se entrelaçam no tecido da vida cotidiana até se tornarem indistinguíveis (WEISER, 1991), onde notase que a geração atual de usuários utiliza a internet de maneira praticamente imperceptível.

Os serviços de comunicação móvel são considerados tecnologias portáteis onipresentes, e os usuários têm uma relação pessoal próxima com os dispositivos envolvidos. Flexibilidade, mobilidade e eficiência estão entre os atributos que solucionam problemas cotidianos e satisfazem os desejos de seus usuários (RAO et al., 2007). As empresas relacionadas aos setores de comunicação estão focadas em boas oportunidades de negócios que são resultado do cumprimento dessas preocupações e necessidades (ABRAHÃO et al., 2016).

Entre os serviços oferecidos hoje, há uma tendência chamada 'pagamento móvel' (ou m-payment). Este processo visa a compra, pagamento ou transferência de valores feitos através do dispositivo móvel, sem a necessidade de dinheiro ou a participação de instituições bancárias (DAHLBERG et al., 2008). De acordo com Karnouskos et al. (2004), dispositivos móveis como telefones celulares ou smartphones servem como um meio pelo qual os pagamentos podem ser iniciados, ativados e/ou confirmados.

Um estudo realizado por Cliquet (2014) mostrou que o celular agora é um companheiro de compras digitais frequentemente utilizado para atividades de pré-compra, tanto fora como dentro da loja, como coleta de informações, leitura e análise de produtos e comparações de preços. O estudo mostrou que o telefone celular também é usado como um facilitador de compras na loja, embora com menor frequência em comparação com as atividades de pré-compra.

Desse modo, nota-se o alto nível de desenvolvimento da tecnologia e o quanto esta tem influenciado no consumo e na satisfação do cliente. Com isso, evidencia-se a importância das empresas implementarem tal tecnologia em suas transações, bem como em seus pontos de venda.

\section{Ponto de venda (PDV) e o mercado atual}

Os objetivos de uma empresa estão direcionados à satisfação das necessidades dos clientes, bem como um consequente alcance das metas organizacionais inicialmente traçadas. Todos os esforços têm o seu ápice quando da compra do produto ou serviço pelo cliente e, em muitas empresas, esse processo se dá no ponto de venda. Strunck (2012) destaca que os pontos de venda são pontos fortes nos processos de criação de valor para uma marca, ressaltando também que neles são entregues as promessas feitas para o cliente.

De acordo com Blessa (2007), ponto de venda (PVD) "é qualquer estabelecimento comercial que exponha serviços ou produtos para a venda aos consumidores". Dessa forma, é importante ponderar que no PVD os consumidores estão propícios ao consumo, sendo estimulados por uma ampla gama de variedades de produtos que podem influenciá-los a um ato de compra final. "A importância do ponto de venda está no fato de ser uma propaganda tridimensional de si mesmo, na qual muitas das decisões são tomadas ou influenciadas in loco" (UNDERHILL, 1999).

Por se tratar do último estágio da cadeia de suprimento, ou seja, a última etapa de um processo onde uma empresa - e seus múltiplos processos de produção - entrega um produto acabado para o consumidor, muitos autores defendem que o ponto de venda se tornou um elo que passou a demandar cada vez mais 
atenção. Ser uma peça fundamental na persuasão do cliente possibilitou ao ponto de venda um papel importante, saindo da condição de coadjuvante e passando a possuir peculiaridades únicas.

A partir da pesquisa de Underhill (1999), pode-se inferir que uma das novas características do ponto de venda está diretamente relacionada a proporcionar experiências cada vez mais multifacetadas que atinjam diretamente as expectativas criadas pelo cliente para, então, efetivar a venda. Diversos estudos foram realizados no intuito de mensurar a experiência dos consumidores de diferentes perspectivas relacionadas ao ponto de venda (DONOVAN et al., 1982; TERBLANCHE et al., 2006; BAKER et al., 2002).

Em seus estudos, Blessa (2010) destaca que "os pontos de venda permitem-nos vivenciar experiências criteriosas de multisensoridade". Ainda de acordo com a autora, o processo decisório não planejado e extremamente rápido que acontece no ponto de venda e a influência dos consumidores estão diretamente relacionados às percepções que o local provoca. Para ela, a visão é responsável por 83\% da percepção dos consumidores, seguida pela audição $(11 \%)$, olfato $(3,5 \%)$, tato $(1,5 \%)$ e paladar, responsável por somente $1 \%$ da percepção identificada pelos consumidores no ponto de venda.

Por se tratar do ponto final da vivência da marca, o PVD passou a alterar a sua forma de exposição, visando a garantia de sucesso para as empresas, buscando inovar nos espaços, nas tecnologias utilizadas e na capacitação de pessoal. Schetz (2012) destaca que a forma de expor e explorar o PDV vem se alterando desde a década de 90, quando a indústria concluiu que o perfil do consumidor havia mudado e que ele esperava ambientes mais experimentais, interativos, conectados e receptivos. Toda essa evolução se dá pelo advento de tecnologias que possibilitaram novas formas de consumir, como é o caso do consumo Mobile, através de smartphones. Com o aumento do uso de aparelhos celulares para a realização de compras, a publicidade móvel na loja pode ser uma forma adicional e eficaz de influenciar a tomada de decisões (KROSCHKE, 2017).

A influência das novas tecnologias vem transformando as formas de compra no ponto de venda, permitindo aos clientes experiências cada vez mais integradas e tecnológicas. Tais mudanças são impulsionadas por novos softwares a elas relacionados: aplicativos, pagamentos móveis, cupons digitais, serviços baseados em geolocalização, entre outros (BOTELHO et al., 2016).

Freitas (2018) sugere que 70\% de todas as decisões de compra são realizadas na loja, dessa forma, o mobile in store aparece como uma importante ferramenta de competitividade. Cabe ressaltar a importância do mobile marketing nesse processo, sendo um conjunto de práticas que permite às organizações comunicarem e se relacionarem com o seu público-alvo de uma forma interativa e relevante através de qualquer dispositivo ou rede móvel (MMA, 2009).

\section{Mobile in store}

Considerando o crescimento exponencial de smartphones e, ao mesmo tempo, a busca dos clientes por produtos e serviços com preços mais baixos, as empresas estão adaptando suas técnicas de marketing para fidelização e vendas de bens e serviços aproveitando a facilidade atual em comprar e consumir por meio do uso dos dispositivos móveis (JARABA et al., 2013). Segundo Coy (2013), os dispositivos tecnológicos estão 
mudando o comportamento de compra do consumidor e as empresas desfrutam desse cenário para anunciar ofertas especiais instantâneas pelo celular, possibilitar o resgate de uma promoção apresentando um código na tela do celular, transmitir mais informações sobre um produto ou dar a chance dos clientes compararem preços de lojas próximas usando aplicativos.

As tecnologias móveis auxiliam o consumidor a tomar decisões durante o processo de compra e potencializam a satisfação do consumidor, pois de acordo com Porter et al. (2017), essas experiências reduzem qualquer incerteza que os clientes possam sentir sobre suas escolhas, encurta o ciclo de vendas e deixa o cliente mais satisfeito.

O uso de tecnologias associadas a plataformas móveis tem estimulado o consumidor a pesquisar, comparar, experimentar e até personalizar produtos e serviços enquanto estão dentro de lojas físicas. Segundo Jara et al. (2012), as novas gerações querem participar da construção do produto e serem capazes de compartilhar suas experiências, e, para entregar esse valor aos consumidores, as empresas estão se movimentando no sentido de oferecer mais dados e tecnologias nas lojas.

Internet Wi-fi, bluetooth, NFC, QR Code, realidade aumentada, realidade virtual, mobile payment, self checkout, sites, aplicativos e redes sociais são exemplos de tecnologias utilizadas em lojas físicas por meio de mobiles, permitindo maior interação com a marca e satisfação do consumidor. Para Coy (2013), essas são as grandes inovações do marketing móvel, as quais possibilitam integrar realidade online e off-line e gerar maiores resultados de marketing para as empresas. Hui et al. (2013) comprovaram em seu estudo que as promoções móveis motivam as compras não planejadas, pois aumentam a duração da visita do consumidor à loja quando impactado por cupons virtuais por exemplo.

Quanto ao cenário de celulares e internet no Brasil, o Instituto Brasileiro de Geografia e Estatística (IBGE) revelou em fevereiro de 2018 que, em 2017, 92,7\% dos lares já contavam com pelo menos uma pessoa com uma linha de telefonia móvel e que $69 \%$ dos entrevistados estavam conectados à rede através de um smartphone.

Em julho de 2018, o Comitê Gestor da Internet no Brasil apontou, a partir de dados levantados pela Hootsuite e We Are Social, que a velocidade da internet móvel no Brasil está abaixo da média mundial, de 16,4 megabytes por segundo contra 21,3 , e que $70 \%$ dos acessos dos brasileiros à internet são oriundas de conexões pré-pagas. Ainda segundo o Comitê, o brasileiro está em 3o lugar no mundo em tempo de permanência na internet, perdendo apenas para Tailândia e Finlândia. Em um dia, o brasileiro fica em média 9 horas e 14 segundos conectado, sendo que durante 4 horas 21 segundos ele usa conexões móveis.

Quando o Comitê analisa os dados por classes, verifica que o acesso à internet pelas classes A e B acontece por diversos dispositivos, já o acesso à internet das classes C e D é realizado exclusivamente pelos celulares, muito influenciado pelo baixo custo de compra dos aparelhos em comparação a computadores e tablets.

Esses dados mostram que a maioria dos brasileiros já usa smartphone e acessa a internet pelo celular, porém a internet contratada no pacote de dados é lenta e limitada pelo plano pré-pago, mas ainda assim o brasileiro costuma permanecer $1 / 6$ do dia conectado pelo celular. Dessa maneira, a rede sem fio gratuita se 
torna relevante no cotidiano da população, gerando oportunidades de marketing quando ofertada dentro das lojas.

Wireless Fidelity ou Wi-Fi se trata de uma rede sem fio para conexão entre dispositivos portáteis, criada pela Wi-fi Alliance e que proporciona conforto aos usuários, pois não precisam ficar limitados ao alcance do fio (BAKARE et al., 2018). Uma pesquisa foi realizada pela Norton Wi-Fi Risk Report em 2017, com 1.000 usuários de Wi-fi de 15 países, inclusive o Brasil, para identificar o comportamento de consumo. A pesquisa apontou que os consumidores não conseguem resistir a um sinal forte de $\mathrm{Wi}$-fi, que $55 \%$ dos entrevistados estariam dispostos a trocar algo por sinal forte de Wi-fi e que $46 \%$ se conectam ou pedem a senha de Wi-fi alguns minutos depois que chegam em restaurantes, hotéis ou outros estabelecimentos. Acreditam que ter sinal de Wi-Fi público é uma obrigação.

A pesquisa relatou também que o Wi-fi é um fator decisivo para a escolha hospedagens (71\%), meios de transportes (46\%), lugares para comer e beber (43\%) e que $49 \%$ precisa do Wi-fi para se locomover (GPS). Por fim, apresenta que 60\% sentem segurança ao usar o Wi-fi público. Quando os consumidores dispõem de internet, então acessam a sites, redes sociais, aplicativos, $Q R$ Code, códigos com link para realidade aumentada para buscar conteúdos e produtos do seu interesse. Portanto, há grande oportunidades para as marcas se aproximarem dos seus públicos através da disponibilização do acesso Wi-fi nas suas lojas.

O QR Code (Quick Response code) é um código de resposta rápida parecido com a função do código de barras: escanear dados. Com um aspecto de matriz preta bidimensional, o QR Code apresenta mais de 7 mil caracteres, enquanto o código de barras, apenas 20, armazenando muito mais informações, dentre mensagens de texto, URLs para sites e vídeos, coordenadas geográficas e número de telefone (CATA et al., 2013). Para acessar o conteúdo do QR Code, basta acionar a câmera de um dispositivo móvel, dispor de internet e um leitor de QR Code. Segundo Cata et al. (2013), os QR Code são encontrados em embalagens de produtos, revistas, museus e até em locais públicos para fornecer informações adicionais aos usuários, cumprindo o papel do marketing de interagir, engajar e estimular o consumidor para uma ação.

Mas o QR Code está indo além de um mero instrumento de informação e marketing. O estudo realizado pela Sociedade Brasileira de Varejo e Consumo (SBVC) e pela AGP Pesquisas Estatísticas, em junho de 2019, mostra o interesse crescente dos comerciantes em adotar o QR Code como forma de pagamento em lojas físicas. De acordo com a pesquisa, no Brasil, $17 \%$ dos consumidores gostariam de pagar suas compras por intermédio de QR Code, porém nenhuma empresa varejista pesquisada utiliza ainda o QR Code. Considerando esse cenário, 82\% dos comerciantes disseram que pretendem usar o QR Code para pagamento nos próximos 12 meses. A Pesquisa anuncia também o lançamento da plataforma de pagamento digital do Itaú Unibanco até setembro de 2019, a qual vai dispensar as máquinas de cartão de crédito, pois funcionará direto por um aplicativo.

Segundo Mallat (2007), o mobile payment é o uso de um dispositivo móvel para realizar uma transação, em que dinheiro ou fundos são transferidos. Pode ocorrer através da internet do mobile, acessando variadas plataformas, com pagamento tradicional por conta bancária, cartão de débito e crédito, ou por meio de tecnologias de proximidade acopladas em chips e aparelhos, que dispensam cartões, como é 
o caso do RFID e do NFC. Essas tecnologias maximizam a conveniência de pagamentos, porque pode-se efetuar a qualquer hora e lugar, sem pegar filas, sem necessidade de carteira ou dinheiro. Além disso, é uma ótima opção para o estabelecimento diminuir despesas com transação.

Near-field communication (NFC), ou Comunicação por Campo de Proximidade (CCP), é uma tecnologia sem fio que conecta dispositivos eletrônicos próximos, por meio de indução eletromagnética, transferindo dados numa curta distância (10 a 20 centímetros), de forma segura e rápida. Desenvolvida pela Philips e Sony em 2002, o NFC funciona de forma similar ao sistema RFID, Radio Frequency Identification (POUSTTCHI, 2009).

Segundo Godoy (2018), a etiqueta RFID e NFC são compostas por estrutura de antena, microchip e envoltório plástico, que identificam e rastreiam dados. São diferentes do código de barras, pois o código de barras é impresso na superfície de uma etiqueta, a leitura acontece em um código de barras por vez, em velocidade e distância pequenas. Tanto o NFC quanto o RFID são usados em dispositivos de aproximação, como cartão de portas em hotel, chaves de carro, transportes públicos, celulares e objetos para controle de acesso e inibição do furto, como roupas. Ambos consomem pouca energia para transmitir dados (15mA).

O RFID tem a possibilidade de identificar vários itens de uma vez só, sem precisar escanear um código de barras ou deslizar sobre uma tarja magnética, é automático. Ele identifica os itens com maior distância e velocidade do que o código de barras, aumentando a produtividade, melhorando o gerenciamento de estoque, reduzindo perdas de vendas e aumentando a satisfação do consumidor (GODOY, 2018).

As diferenças entre NFC e RFID, segundo a empresa Tag Id, estão no modo da comunicação e no alcance do sinal. Enquanto no NFC a comunicação é bilateral, sua etiqueta permite ser lida por um dispositivo e também lê informações de outros dispositivos, no RFID a comunicação é unilateral, sendo só lida. Já em relação ao alcance, o NFC produz sinal de até $10 \mathrm{~cm}$, dificultando interferências; e o RFID chega a mais de 10 metros.

Pousttchi (2009) afirma que as melhores utilizações para o NFC são para acesso a conteúdos digitais, tickets e pagamentos móveis, porque essa tecnologia opera em emulação de cartões (cartão sem contato), leitor de etiquetas RFID e para troca de informações, como imagens, números de telefone, arquivos de áudio e vídeo, com outros dispositivos. Com isso, o NFC é capaz de integrar serviços e ofertas ao comércio eletrônico mobile, se tornando um inovador conceito de marketing e vendas.

Uma outra tecnologia sem fio com transmissão por radiofrequência é o Bluetooth. Seu sinal alcança até $100 \mathrm{~m}$, transmite dados numa velocidade de $2,1 \mathrm{Mbps}$ e utiliza até $13 \mathrm{~mA}$ de energia. Diferente do NFC e RFID que são automáticos, o Bluetooth precisa ser pareado nos mobiles manualmente (SAB et al., 2013). Em ações de marketing onde os clientes estejam numa maior distância da transmissão do sinal, o Bluetooth funciona melhor do que o NFC.

Desenvolvida pela Apple em 2013, o iBeacon é um dispositivo iOs que usa o Bluetooth Low Energy para transmitir sinais de radiofrequência para iPhone 4S (ou mais avançados), iPod touch (5a geração), iPad (3a geração ou posterior) ou iPad mini. Como as etiquetas RFID, o iBeacon também é unidirecional, ou seja, transmite sinal para um aparelho, mas não recebe informações dele. Segundo a Apple, a iBeacon possibilita 
que um aplicativo identifique a entrada de uma cliente numa loja e emita uma mensagem de boas-vindas para ele, por exemplo, estimulando-o a usar o aplicativo que mostra a localização do cliente na loja. Então, o estabelecimento cria a oportunidades para apresentar anúncios de promoção e informações de produtos à medida que o cliente se aproxima dos corredores que os produtos estão dispostos. Para Kotler (2017), tecnologias como NFC e iBeacon geram uma experiência atraente para os consumidores.

Ainda com o objetivo de fidelizar os clientes, e reduzir custos para se diferenciar no mercado, as empresas têm apostado em tecnologias de autoatendimento (self-service technologies - SSTs) para pagamento automático, também chamado de self-checkout. Essa modalidade de atendimento consiste no processo do consumidor registrar suas compras no leitor de código de barras, as embalar e pagá-las sem auxílio de um atendente (PEDROSO, 2013). No estudo realizado, Pedroso (2013) atesta que os atributos de rapidez, confiança, facilidade e prazer de uso e controle influenciam positivamente a qualidade do selfservice, além de influenciar a satisfação e a intenção de uso do self-checkout em supermercados, alvo da sua pesquisa. Considerando que os clientes e os varejistas ganham com a tecnologia, é uma grande oportunidade de se adotar totens de self-checkout em pontos de venda dos mais variados segmentos.

A realidade aumentada também é uma tecnologia que está contribuindo para atratividade e consumo. Porter et al. (2017) a definem como tecnologias que sobrepõe dados digitais (2D) a imagens do mundo real (3D), apresentando informações diretamente no contexto da aplicação para o consumidor, acelerando a capacidade humana de absorver informações e tomar decisões, inclusive, de compra.

Ainda segundo Porter et al. (2017), as aplicações de realidade aumentada são entregues através de dispositivos móveis, como smartphones e tablets. Marcadores, como códigos, logotipos ou rótulos, são colocados nos objetos e digitalizados pelo usuário com a câmera do mobile e aplicativo da realidade aumentada. E, então, objetos e cenários se projetam para o ambiente em que o usuário está.

A realidade aumentada é vista com mais frequência no ramo do entretenimento, como nos filtros do Snapchat e em jogos como Pokémon Go, mas a tecnologia já está sendo aplicada em diversas áreas, como recursos humanos (em integração, ambientação e treinamento de funcionários), desenvolvimento de produtos, marketing e vendas (demonstração de produtos virtuais em cenários reais, mais informações sobre produtos), pós-venda (manuais de instrução e atendimento técnico remoto).

Assim como a realidade aumentada, a realidade virtual também consiste em técnicas computacionais que levam em conta o espaço tridimensional, explora múltiplos sentidos como visão, audição e tato e permite que o usuário interaja em tempo real (RIBEIRO et al., 2011). Na realidade virtual, o usuário visualiza o mundo virtual por meio de telas acopladas a capacetes (HMD) ou em salas com multiprojeção (cavernas), que são métodos não imersivos, possibilitando o usuário manter o senso de presença na realidade, mas também são usados outros dispositivos que projetam o usuário completamente para o mundo virtual.

Diante desse cenário, percebe-se uma variedade de tecnologias disponíveis que podem ser adotadas nos pontos de venda para maximizar vendas, interação com os clientes e o poder da marca. 


\section{METODOLOGIA}

Visando responder à questão norteadora desta pesquisa e no intuito de consolidar a construção argumentativa que este trabalho se propõe a fazer, apresenta-se os procedimentos metodológicos e classificações deste estudo, a saber: Inicialmente, considera-se esta pesquisa como uma investigação teóricoempírica, haja vista que serão realizadas reflexões sobre a teoria do Mobile in Store e a sua prática a partir dos achados na pesquisa bibliográfica (literatura atual) e na pesquisa de campo (observação participante e roteiro estruturado).

A importância da revisão da literatura é inquestionável, uma vez que, serão feitas análises e reflexões a partir do link teórico com os achados na prática. Além disso, pretende-se com a pesquisa de campo, a observação e coleta de dados sobre os fenômenos estudados. Somado a isto, as reflexões da teoria com a prática proporcionaram maior respaldo na elaboração das conclusões do estudo.

Quanto à natureza, esta pesquisa adota o método qualitativo. Sendo classificada quanto aos fins como descritiva, exploratória e aplicada. Segundo Merriam (2009), o procedimento exploratório de investigação teórico-empírica se guia pela compreensão da realidade por meio de exemplos em conjunto com a literatura. Além disso, Nielsen (2004) afirma que a pesquisa qualitativa apresenta resultados mais detalhados e consistentes, o que tornará este estudo mais relevante.

Pretende-se por meio do método qualitativo, descrever, interpretar e compreender os sujeitos de pesquisa. Para tanto, é proposto a utilização da observação participante e um roteiro estruturado na coleta de dados. Vale ressaltar que, este tipo de técnica é mais adequado para uma amostra reduzida, por possibilitar o aprofundamento do que foi observado e coletado.

Neste estudo, os lócus empiricus e/ou sujeitos são empresas de um shopping center, mais especificamente, funcionários das marcas selecionadas que estão localizadas na cidade de João Pessoa, Paraíba. O número de sujeitos da pesquisa foi de trinta e duas (32) empresas. Todos foram acessados por tipicidade, isto é, escolhidos pela sua representatividade. Diante desse contexto, esta pesquisa pode ser classificada quanto aos meios como um estudo de multicasos, pois analisou a temática proposta em várias empresas de diversos segmentos e tamanhos (porte físico).

Vale ressaltar, que este estudo considerou a classificação das empresas entre 'Lojas Âncora' (grande porte) e 'Lojas Satélite' (pequeno porte). De acordo com Gomide et al. (2007), a Loja Âncora é uma loja em um centro comercial (shopping center) que tem um tamanho maior em relação as lojas comuns (lojas satélites, fast-food e quiosques) e que pode atrair um público maior ao shopping, pois geralmente é conhecida nacionalmente e internacionalmente. Além disso, são consideradas indispensáveis, pois geram atratividade aos consumidores, tendo importância fundamental no funcionamento desses centros comerciais. Já a Loja Satélite possui um tamanho menor, e no geral, trabalham com um tipo de produto/serviço mais específico (Quadro 1).

Para a coleta dos dados, foi elaborado e adotado um roteiro estruturado. Tal instrumento de pesquisa, contempla dezesseis (16) itens e foi confeccionado com base na literatura atual sobre Mobile in 
Store (Apêndice A). Seu objetivo é servir como um guia para identificar e analisar o uso das novas tecnologias móveis e a experiência no Ponto de Venda (PDV) dos consumidores. Logo, a construção e adoção deste roteiro se fez apropriado aos objetivos desta pesquisa. Além disso, houve a observação participante das autoras, que ocorreu de forma concomitante à aplicação do roteiro.

Quadro 1: Empresas selecionadas para o estudo.

\begin{tabular}{|c|c|c|c|}
\hline \multicolumn{4}{|c|}{ Sujeitos da pesquisa } \\
\hline Empresa & Loja Âncora & Loja Satélite & Tamanho (porte) \\
\hline Adidas & & $\mathrm{x}$ & Pequena \\
\hline Alecrim & & $x$ & Pequena \\
\hline Arezzo & & $\mathrm{X}$ & Pequena \\
\hline Camicado & $\mathrm{X}$ & & Grande \\
\hline C\&A & $X$ & & Grande \\
\hline Centauro & $x$ & & Grande \\
\hline Chilli Beans & & $x$ & Pequena \\
\hline Chocolates Brasil Cacau & & $x$ & Pequena \\
\hline Delta Expresso & & $x$ & Pequena \\
\hline Ecológica & & $x$ & Pequena \\
\hline Farm & & $x$ & Pequena \\
\hline Kalunga & $x$ & & Grande \\
\hline Kopenhagen & & $x$ & Pequena \\
\hline Le Biscuit & $x$ & & Grande \\
\hline Livraria Leitura & $x$ & & Grande \\
\hline Lojas Americanas & $\mathrm{X}$ & & Grande \\
\hline Magazine Luíza & $x$ & & Grande \\
\hline Marisa & $x$ & & Grande \\
\hline Morana & & $x$ & Pequena \\
\hline Nagem & & $x$ & Pequena \\
\hline Narciso & $X$ & & Grande \\
\hline O Boticário & & $x$ & Pequena \\
\hline Pandora & & $\mathrm{X}$ & Pequena \\
\hline Polishop & $\mathrm{X}$ & & Grande \\
\hline Quem disse, Berenice? & & $x$ & Pequena \\
\hline Renner & $\mathrm{X}$ & & Grande \\
\hline Riachuelo & $x$ & & Grande \\
\hline Ri Happy & $\mathrm{X}$ & & Grande \\
\hline Saraiva & $\mathrm{X}$ & & Grande \\
\hline Tok Stok & $\mathrm{X}$ & & Grande \\
\hline The Body Shop & & $\mathrm{x}$ & Pequena \\
\hline Vivara & & $x$ & Pequena \\
\hline
\end{tabular}

Por fim, para a análise de dados, foi realizada uma análise interpretativa/descritiva, a partir das categorias utilizadas para elaborar o roteiro da observação participante. Foi feita uma análise da teoria comparando-a com a prática encontrada nas empresas que se apresenta na coleta de dados. Dessa forma, temos uma discussão que permite apresentar um panorama do uso de tecnologia mobile nos pontos de venda de lojas de um shopping de João Pessoa-PB.

\section{RESULTADOS E DISCUSSÃO}

Com o intuito de investigar como se dá a experiência mobile in store em lojas de um shopping center de João Pessoa, foram colhidos dados por meio da observação participante guiada por um roteiro de pesquisa estruturado que foi construído a partir da teoria acerca de tecnologias mobile e suas variáveis. Para tanto, foram traçadas categorias que emergiram da teoria utilizada no roteiro de pesquisa para que fosse possível estruturar a análise e discutir os resultados encontrados. São as categorias: Uso de tecnologias mobile, 
Capacitação dos colaboradores, Ambiente da loja, Relacionamento com o cliente e Canais de venda.

De modo geral, pode-se perceber que as tecnologias mobile e as variáveis que as envolve são pouco utilizadas nas lojas do shopping investigado, mesmo nos estabelecimentos que trabalham diretamente com tecnologia e ainda que elas possam ser determinantes na satisfação do consumidor (PORTER e HEPPELMANN, 2017). A seguir, são analisadas cada uma das categorias, os quadros trazem as respostas analisadas na observação participante, sendo Sim para quando a loja adota a tecnologia ou quando o item foi satisfatório e Não para quando a loja não adota a tecnologia ou o item não foi satisfatório.

\section{Uso de tecnologias mobile}

Cada vez mais presentes no dia a dia das pessoas, as tecnologias móveis, representadas principalmente pelos smartphones, estão transformando as formas com que elas se relacionam e se comportam. Visualizando esse cenário, as empresas estão cada vez mais tecnológicas, buscando adaptar suas técnicas de marketing para fidelização e vendas de bens e serviços, se aproveitando da facilidade que os consumidores atuais têm na utilização dos dispositivos móveis (JARABA et al., 2013).

Algumas inovações tecnológicas têm sido cada vez mais difundidas. Internet Wi-fi, $Q R$ Code, realidade aumentada, realidade virtual, mobile payment, self checkout, sites, aplicativos e redes sociais são algumas das tecnologias que podem ser utilizadas por meio de mobile para permitir maior interação da marca com o consumidor, além de serem as grandes inovações do marketing móvel (COY, 2013), tornando-se vantagem competitiva para muitas empresas.

Apesar da percepção de mudança de cenário no que tange ao uso das tecnologias integradas aos dispositivos mobile, as empresas ainda investem pouco nas inovações do marketing móvel. Como mostra o quadro abaixo, tecnologias como $Q R$ Codes, realidade aumentada e self checkout são praticamente inexistentes nas empresas do shopping pesquisado.

Quadro 3: Uso de tecnologias mobile.

\begin{tabular}{|c|c|c|c|c|c|c|}
\hline Empresa & $\begin{array}{l}\text { QRCodes } \\
\text { nos } \\
\text { produtos }\end{array}$ & $\begin{array}{c}\text { Usa Realidade } \\
\text { Aumentada } \\
\text { no PDV }\end{array}$ & $\begin{array}{c}\text { Acesso a } \\
\text { informação dos } \\
\text { produtos via } \\
\text { plataforma para } \\
\text { celular }\end{array}$ & $\begin{array}{c}\text { É possível } \\
\text { comparar } \\
\text { valores do PVD } \\
\text { com as lojas } \\
\text { online }\end{array}$ & $\begin{array}{c}\text { A loja dispõe } \\
\text { de Mobile- } \\
\text { Payment no } \\
\text { PVD }\end{array}$ & $\begin{array}{c}\text { Possui Mobile- } \\
\text { Checkout, self- } \\
\text { checkout ou o } \\
\text { escaneamento por } \\
\text { celular }\end{array}$ \\
\hline Adidas & Não & Não & Não & Não & Não & Não \\
\hline Alecrim & Não & Não & Sim & Não & Não & Não \\
\hline Arezzo & Não & Não & Sim & Sim & Sim & Não \\
\hline Camicado & Não & Não & Não & Sim & Sim & Não \\
\hline$C \& A$ & Não & Não & Sim & Sim & Sim & Não \\
\hline Centauro & Não & Não & Sim & Sim & Não & Sim \\
\hline Chilli Beans & Não & Não & Não & Sim & Não & Não \\
\hline $\begin{array}{l}\text { Chocolates } \\
\text { Brasil Cacau }\end{array}$ & Não & Não & Não & Não & Sim & Não \\
\hline $\begin{array}{c}\text { Delta } \\
\text { Expresso }\end{array}$ & Não & Não & Sim & Não & Não & Não \\
\hline Ecológica & Não & Não & Não & Sim & Não & Não \\
\hline Farm & Não & Não & Não & Sim & Sim & Não \\
\hline Kalunga & Não & Não & Sim & Sim & Sim & Não \\
\hline Kopenhagen & Não & Não & Sim & Não & Não & Não \\
\hline Le Biscuit & Não & Não & Sim & Sim & Não & Não \\
\hline Livraria & Não & Não & Não & Não & Não & Não \\
\hline
\end{tabular}




\begin{tabular}{|c|c|c|c|c|c|c|}
\hline Leitura & & & & & & \\
\hline $\begin{array}{c}\text { Lojas } \\
\text { Americanas }\end{array}$ & Sim & Não & Sim & Sim & Sim & Não \\
\hline $\begin{array}{c}\text { Magazine } \\
\text { Luíza }\end{array}$ & Não & Não & Sim & Sim & Sim & Não \\
\hline Marisa & Não & Não & Não & Sim & Não & Não \\
\hline Morana & Não & Não & Não & Não & Não & Não \\
\hline Nagem & Sim & Não & Não & Sim & Sim & Não \\
\hline Narciso & Não & Não & Sim & Não & Não & Não \\
\hline O Boticário & Não & Não & Não & Sim & Sim & Não \\
\hline Pandora & Não & Não & Sim & Sim & Sim & Não \\
\hline Polishop & Não & Não & Sim & Sim & Não & Não \\
\hline $\begin{array}{c}\text { Quem disse, } \\
\text { Berenice? }\end{array}$ & Não & Não & Sim & Sim & Sim & Não \\
\hline Renner & Não & Não & Sim & Sim & Sim & Não \\
\hline Riachuelo & Sim & Não & Sim & Sim & Não & Não \\
\hline Ri Happy & Não & Não & Não & Não & Não & Não \\
\hline Saraiva & Não & Não & Não & Sim & Não & Não \\
\hline Tok Stok & Sim & Não & Sim & Sim & Sim & Sim \\
\hline $\begin{array}{c}\text { The Body } \\
\text { Shop }\end{array}$ & Não & Não & Sim & Sim & Sim & Não \\
\hline Vivara & Não & Não & Sim & Sim & Sim & Sim \\
\hline
\end{tabular}

Utilizados para fornecer informações adicionais sobre produtos e suas características, revistas, museus e outros, o $Q R$ Code é uma ferramenta que cumpre o papel de interação com o cliente que o marketing exige (CATA et al., 2013). A partir das respostas obtidas com a pesquisa, foi possível identificar que somente as empresas Riachuelo, Nagen e Lojas Americanas possuem o código em seus produtos. Entretanto, ao ser feito o teste sobre o bom funcionamento, foi observado que na Nagen o direcionamento do $Q R$ Code é feito para uma página com informações dos produtos, não sendo possível acessar o preço destes. Nas outras duas lojas, foi perceptível que os códigos funcionam e levavam os clientes aos sites das empresas, que conta com todos os detalhes do produto e seus respectivos preços e condições. Na Tok Stok, o QR Code foi encontrado em apenas alguns dos produtos.

A desinformação a respeito da ferramenta foi de fácil percepção em algumas empresas. Na Livraria Leitura, por exemplo, ao indagar uma vendedora sobre o $Q R$ Code, foi possível observar que a mesma não possuía nenhum conhecimento sobre, sendo necessário informá-la a respeito de sua funcionalidade. Na prática, vê-se que os colaboradores das empresas atribuem a tarefa de informação sobre os produtos aos sites e redes sociais, e desconhecem a ferramenta, como é o caso da The Body Shop, onde as atendentes explicaram que todas as informações podem ser encontradas no site e aplicativo da organização.

Essa disponibilização de acesso à informação dos produtos via plataforma para celular também foi questão de pesquisa. Algumas das empresas possuem sites com as informações sobre os produtos, bem como sobre condições de pagamento e outros. No entanto, em empresas como Narciso et al., as informações constantes nos sites são bastante limitadas, onde muitos produtos não estavam disponíveis; disponibilizava apenas foto e código do produto e, onde não foi possível consultar preços ou qualquer outra informação mais especifica (tampouco existe a possibilidade de realizar compras on-line), respectivamente.

Tendo como função também a de propagar as informações sobre a marca, o marketing se utiliza de ferramentas como os aplicativos para dispositivos móveis e redes sociais para tal. Nas empresas em questão, algumas ainda não utilizam os artifícios da tecnologia para alavancar as suas vendas e melhorar o 
relacionamento com o cliente, ou o fazem de maneira ainda incipiente. Na Ecológica, por exemplo, não há nenhuma plataforma com informações dos produtos, caso o cliente queira saber mais sobre algo, pode mandar mensagens através da rede social WhatsApp. Na Alecrim, as informações sobre os produtos podem ser adquiridas apenas acessando o Instagram da loja. Na Ri Happy, foi informado que a empresa prioriza o atendimento presencial na loja, com vendedores capacitados para apoiar o consumidor nas transações tradicionais, mas não nas experiências mediadas pelo uso das TICs.

Um outro problema observado em algumas empresas diz respeito aos seus sites. Delta Expresso, Adidas, Kopenhagen e Camicado, por exemplo, possuem sites institucionais, que se limitam às informações gerais dos produtos, e registram e informam apenas os endereços das franquias mais próximas. Esse fato limita a possibilidade de comparação de preços, por exemplo, onde o cliente não tem a informação necessária para ter opção de buscar os produtos mais baratos. A não utilização de lojas e-commerce, como é o caso da Alecrim e da Livraria Leitura, também limita o poder de decisão dos clientes. Empresas como Riachuelo, Kalunga e Lojas Americanas ofertam esse serviço com eficácia para os clientes. A Tok Stok possui um diferencial neste requisito, onde o cliente pode procurar o valor do produto no site e comparar com o do PDV, e caso o valor do site esteja mais baixo, ele pode comprar e fazer a retirada na loja física.

Utilizar tecnologias mobile que tornem a relação cliente/empresa mais próxima, ajudando na flexibilidade e satisfazendo os desejos de seus usuários cria vantagem competitiva entre as empresas. Alguns exemplos de tecnologias que tornam isso possível são a realidade aumentada, mobile payment e selfcheckout. A realidade aumentada, que apresentaria informações para o consumidor, acelerando a capacidade de absorvê-las e tomar decisões de compra não é utilizada por nenhuma das empresas pesquisadas. Na Ri Happy, embora obtida a informação de que as lojas da rede têm realizado campanhas promocionais apoiadas no uso da realidade aumentada, a exemplo de ação específica de páscoa dirigida às crianças, os atendentes foram taxativos ao informar que a loja não dispunha da tecnologia.

O modelo de self-checkout, onde o cliente realiza todo o processo de registro e pagamento de suas compras sem o auxílio de atendentes também não foi observado em nenhuma das empresas pesquisadas no shopping em questão. O pagamento móvel, embora ainda incipiente em muitos locais, é realizado em algumas das empresas. Na Chocolates Brasil Cacau, Renner, Tok Stok, Kalunga, Camicado, Nagen, O Boticário, Magazine Luiza e Pandora, é possível a realização de pagamento através do cartão online disponibilizado pelo banco do cliente. Essa função maximiza a conveniência de pagamentos, sem que haja a necessidade de carteira ou dinheiro, sendo também uma opção para a empresa diminuir suas despesas com transações.

Os consumidores estão cada vez mais exigentes e querem participar da construção do produto e serem capazes de compartilhar suas experiências (Jara et al., 2012), assim, faz-se necessário que as empresas busquem nos dispositivos móveis e suas tecnologias, as experiências que reduzam as incertezas dos clientes sobre suas escolhas e encurte o ciclo de vendas, deixando o cliente cada vez mais satisfeito.

\section{Capacitação dos colaboradores}

Os recursos tecnológicos são essenciais para alcançar resultados a partir da adoção de tecnologias 
mobile nos pontos de venda. No entanto, é importante atentar para que os recursos humanos estejam corretamente alinhados, pois ainda que sejam adotados os melhores recursos tecnológicos, esses não terão eficiência se não houver uma boa capacitação dos funcionários que os administrarão.

No shopping analisado, percebe-se que em parte das lojas pesquisadas não possui colaboradores bem capacitados para utilizar tecnologias mobile ou saber informar sobre elas. Ainda assim, a maneira como eles conduziram determinadas situações foi considerada satisfatória, pois a simpatia e boa vontade em ajudar se destacaram. Em algumas lojas foi possível observar que os colaboradores possuíam capacitação para atender as questões observadas, quais foram: analisar se eles estavam equipados com celular ou tablet para que pudessem consultar o perfil do cliente, questionar sobre como baixar o aplicativo da loja no celular e questionar sobre como realizar uma compra pelo celular.

A utilização de tecnologias mobile em pontos de venda representa uma oportunidade para expandir a oferta de produtos e a maneira como estes são vendidos (COY, 2013). Estratégias de fácil aplicação, como por exemplo conhecer melhor o consumidor por meio de um cadastro que pode ser acessado por uma ferramenta como celular ou tablete, pode garantir ao colaborador um acesso mais completo ao cliente, se ele entender melhor seus interesses e outras informações sem que fosse necessário se ausentar para consultar o cadastro em um computador, por exemplo. No entanto, das 19 empresas analisadas, apenas duas - CeA e Magazine Luiza - possuíam colaboradores que adotavam essa estratégia, como é perceptível no quadro abaixo.

Quadro 4: Capacitação dos colaboradores.

\begin{tabular}{|c|c|c|c|}
\hline Empresa & $\begin{array}{l}\text { Equipados com celular } \\
\text { ou tablet }\end{array}$ & $\begin{array}{l}\text { Atendente soube explicar como } \\
\text { baixar o app no celular }\end{array}$ & $\begin{array}{c}\text { Atendente soube explicar como realizar } \\
\text { a compra pelo celular }\end{array}$ \\
\hline Adidas & Não & Não & Não \\
\hline Alecrim & Não & Não & Não \\
\hline Arezzo & Não & Não & Não \\
\hline Camicado & Não & Não & Sim \\
\hline C\&A & Sim & Não & Não \\
\hline Centauro & Não & Sim & Sim \\
\hline Chilli Beans & Não & Sim & Sim \\
\hline $\begin{array}{c}\text { Chocolates Brasil } \\
\text { Cacau }\end{array}$ & Não & Não & Não \\
\hline Delta Expresso & Não & Não & Não \\
\hline Ecológica & Não & Não & Não \\
\hline Farm & Não & Sim & Sim \\
\hline Kalunga & Não & Sim & Sim \\
\hline Kopenhagen & Não & Não & Não \\
\hline Le Biscuit & Não & Não & Não \\
\hline Livraria Leitura & Não & Não & Não \\
\hline Lojas Americanas & Não & Sim & Sim \\
\hline Magazine Luíza & Sim & Sim & Sim \\
\hline Marisa & Não & Sim & Sim \\
\hline Morana & Não & Não & Não \\
\hline Nagem & Não & Não & Não \\
\hline Narciso & Não & Não & Não \\
\hline O Boticário & Não & Sim & Sim \\
\hline Pandora & Não & Sim & Sim \\
\hline Polishop & Não & Não & Sim \\
\hline $\begin{array}{l}\text { Quem disse, } \\
\text { Berenice? }\end{array}$ & Não & Não & Sim \\
\hline Renner & Não & Sim & Não \\
\hline Riachuelo & Não & Sim & Sim \\
\hline
\end{tabular}




\begin{tabular}{|c|l|l|l|}
\hline Ri Happy & Não & Não & Sim \\
\hline Saraiva & Não & Sim & Não \\
\hline Tok Stok & Não & Sim & Sim \\
\hline The Body Shop & Não & Sim & Sim \\
\hline Vivara & Não & Não & Não \\
\hline
\end{tabular}

No que se refere à capacitação sobre informações acerca de como baixar o aplicativo da loja, algumas não o possuem como a Alecrim presentes, e outras possuem, mas seus vendedores não se interessaram em transmitir informações que encorajassem a ação, tais como Arezzo, CeA, Le Biscuit e Vivara, enquanto outras como a Centauro, Farm, The body shop e Tok Stok se destacaram quanto à solicitude em atender bem e conhecimento acerca das tecnologias que a loja utiliza.

O marketing mobile se estrutura numa perspectiva de integração on-line e offline que exige que as empresas se adaptem para atender às novas exigências dos consumidores, propensos a realizar compras não somente no ponto de venda, mas de qualquer lugar (COY, 2013). A confiança nas tecnologias mobile foi crescendo ao longo do tempo, garantindo que os consumidores se sentissem seguros em comprar on-line agregando vantagens, tais como a comodidade. Um atributo que o ponto de venda ainda se sobressai às compras on-line encontra-se justamente no atendimento, por isso é importante atentar para a contratação de colaboradores simpáticos e cordiais, capacitados a atender o cliente de maneira a superar suas expectativas e sua experiência on-line.

Quando questionados a respeito de como realizar uma compra on-line, a maior parte dos vendedores não demonstrou muito interesse, justamente por se tratar de franquias, onde a venda on-line na maioria das vezes não se reverterá em lucro direto para a unidade e, consequentemente, não gerará comissão no seu salário. Na C\&A por exemplo, o vendedor se retirou ao ser questionado sobre como realizar compras no aplicativo, mas nas lojas Americanas, o vendedor ensinou como fazer para realizar a compra do início ao fim.

\section{Ambiente da loja}

O ambiente físico da loja, também denominado por alguns autores de servicescape, pode ser projetado para proporcionar uma experiência de compra que satisfaça consumidores e auxilie a empresa a alcançar seus objetivos (BITNER, 1992). Combinado com as tecnologias mobile, o ambiente da loja pode exercer uma influência positiva e desejo de permanência no lugar e de finalização de compra.

Na prática, no entanto, observa-se que as empresas não se adequam à integração das tecnologias mobile ao ambiente da loja. Essa premissa pode ser provada analisando o quadro abaixo, que constata que poucas são as lojas analisadas que disponibilizam internet móvel e nenhuma adota a tecnologia de orientação geográfica por mapas.

Quadro 5: Ambiente da loja.

\begin{tabular}{|c|c|c|}
\hline Empresa & Oferta de wi-fi no PDV & Orientação geográfica por maps \\
\hline Adidas & Não & Não \\
\hline Alecrim & Sim & Não \\
\hline Arezzo & Não & Não \\
\hline Camicado & Não & Não \\
\hline C\&A & Sim & Não \\
\hline Centauro & Não & Não \\
\hline
\end{tabular}




\begin{tabular}{|c|c|c|}
\hline Chilli Beans & Não & Não \\
\hline Chocolates Brasil Cacau & Não & Não \\
\hline Delta Expresso & Sim & Não \\
\hline Ecológica & Não & Não \\
\hline Farm & Sim & Não \\
\hline Kalunga & Não & Não \\
\hline Kopenhagen & Não & Não \\
\hline Le Biscuit & Não & Não \\
\hline Livraria Leitura & Não & Não \\
\hline Lojas Americanas & Não & Não \\
\hline Magazine Luíza & Sim & Não \\
\hline Marisa & Não & Não \\
\hline Morana & Sim & Não \\
\hline Nagem & Não & Não \\
\hline Narciso & Não & Não \\
\hline O Boticário & Não & Não \\
\hline Pandora & Não & Não \\
\hline Polishop & Não & Não \\
\hline Quem disse, Berenice? & Não & Não \\
\hline Renner & Não & Não \\
\hline Riachuelo & Sim & Não \\
\hline Ri Happy & Não & Não \\
\hline Saraiva & Não & Não \\
\hline Tok Stok & Sim & Não \\
\hline The Body Shop & Sim & Não \\
\hline Vivara & Não & Não \\
\hline
\end{tabular}

Os dados coletados na observação participante permitiram analisar que nas lojas Magazine Luiza, Morana e The body shop havia wi-fi, mas não havia sinalização sobre o wi-fi free, de todo modo, as colaboradoras não sabiam informar a rede e senha. Na Saraiva, Arezzo e Kalunga foi informado que poderia ser utilizado a wi-fi do shopping, sendo que na Marisa o vendedor sugeriu a mesma coisa, e acrescentou que a conexão era bastante falha. A Nagem, apesar de ser uma loja de produtos tecnológicos, não conta com wifi. Na Tok Stok solicitamos na entrada da loja e fomos atendidas muito rapidamente. Na Riachuelo, para ter acesso ao wi-fi é preciso cadastrar o CPF do cliente e em seguida é enviada uma mensagem informando que um cartão da loja foi pré-aprovado para você.

A estratégia utilizada pela Riachuelo pode ser bastante efetiva para a concretização de metas de vendas, estabelecendo uma conexão adicional com o consumidor. A tecnologia de utilizar mapas ao longo dos pontos de venda disponibilizando orientação geográfica móvel on-line via aplicativo ou similar nos setores da loja, poderia possibilitar ao consumidor localizar o produto mais facilmente, e assim lhe oferecer uma independência e consequente satisfação (PORTER et al., 2017) porém essa tecnologia realmente não foi adotada por nenhuma loja.

\section{Relacionamento com o cliente}

O avanço da tecnologia possibilita, cada vez mais, uma maior interação entre os clientes e as empresas. Nesse sentido, ações de relacionamento com o cliente no ponto-de-venda (PDV) são imprescindíveis para satisfazer a experiência do consumidor em loja e, consequentemente, alavancar as vendas da empresa.

Segundo Strunck (2012), os pontos de venda podem ser utilizados de forma estratégica, ou seja, com 
o objetivo de criar valor para a empresa e fornece um ambiente favorável para o consumo, isto porque grande parte das decisões dos clientes são tomadas ou influenciadas in loco. Dessa forma, entende-se que no PDV podem existir ações que favoreçam o bom relacionamento com o cliente, especialmente quando a empresa utiliza a tecnologia mobile a favor dessa interação (UNDERHILL, 1999; BLESSA, 2007).

Corroborando com este pensamento, Porter et al. (2017) afirmam que as tecnologias móveis auxiliam o consumidor a tomar decisões durante o processo de compra e potencializam a satisfação do consumidor. Dessa forma, essas experiências reduzem qualquer incerteza que os clientes possam sentir sobre suas escolhas, reduz o ciclo de vendas e favorece a satisfação do consumidor.

Existem diversas estratégias para facilitar o relacionamento com o cliente no ponto-de-venda. Como por exemplo, a loja pode ter um aplicativo próprio (ou enviar mensagem SMS etc.) que disponibilize descontos e ofertas (personalizados ou não) direto ao smartphone dos consumidores assim que ele é identificado no PDV. Vale ressaltar que, independente da estratégia escolhida pela empresa, o objetivo é sempre o mesmo: utilizar a tecnologia mobile de forma eficaz para influenciar a tomada de decisão dos consumidores (KROSCHKE, 2017).

O Quadro 6 abaixo aborda as empresas pesquisadas. Apesar da teoria retratar a importância da adoção de estratégias no ponto-de-venda que aproxime a tecnologia mobile e o cliente em loja, podemos observar neste estudo que das 32 empresas pesquisadas, 29 ainda não aderiram a essas estratégias.

Em contrapartida, as 3 empresas que trabalham com o mobile in store percebem que esse tipo de estratégia no ponto-de-venda pode atrair mais consumidores às compras.

Quadro 6: Relacionamento com o cliente.

\begin{tabular}{|c|c|}
\hline Empresa & Cupons digitais para o smartphone do cliente no PDV \\
\hline Adidas & Não \\
\hline Alecrim & Não \\
\hline Arezzo & Não \\
\hline Camicado & Não \\
\hline$C \& A$ & Sim \\
\hline Centauro & Sim \\
\hline Chilli Beans & Não \\
\hline Chocolates Brasil Cacau & Não \\
\hline Delta Expresso & Não \\
\hline Ecológica & Não \\
\hline Farm & Não \\
\hline Kalunga & Não \\
\hline Kopenhagen & Não \\
\hline Le Biscuit & Não \\
\hline Livraria Leitura & Não \\
\hline Lojas Americanas & Sim \\
\hline Magazine Luíza & Não \\
\hline Marisa & Não \\
\hline Morana & Não \\
\hline Nagem & Não \\
\hline Narciso & Não \\
\hline O Boticário & Não \\
\hline Pandora & Não \\
\hline Polishop & Não \\
\hline Quem disse, Berenice? & Não \\
\hline Renner & Não \\
\hline Riachuelo & Não \\
\hline Ri Happy & Não \\
\hline
\end{tabular}




\begin{tabular}{|c|l|}
\hline Saraiva & Não \\
\hline Tok Stok & Não \\
\hline The Body Shop & Não \\
\hline Vivara & Não \\
\hline
\end{tabular}

Conforme pode ser observado no quadro acima, apesar da teoria retratar a importância do uso eficiente das tecnologias mobile in store junto ao relacionamento com o cliente, apenas a C\&A, a Centauro e as Lojas Americanas utilizam essas tecnologias para se comunicar com os seus consumidores em loja. A C\&A, por exemplo, aplica a estratégia de 'cupom de desconto' no valor de $\mathrm{R} \$ 15,00$ reais assim que o cliente acessa o Wi-Fi da loja. Tal crédito pode ser utilizado em todos os produtos da loja. Acredita-se que tal benefício estimule a venda, além de influenciar o poder de decisão e satisfação do consumidor no ponto-de-venda.

Já a Centauro e a Lojas Americanas oferecem descontos exclusivos, por meio do aplicativo da empresa, enquanto o cliente circula na loja física. A estratégia visa estimular o consumo e aumentar o poder de decisão de compra do cliente. Além disso, é possível receber informes promocionais sobre descontos e de outras ações que ainda irão ocorrer.

Dessa forma, podemos verificar que as marcas que utilizam as tecnologias móveis a favor do relacionamento com o cliente no PDV são consideradas de grande porte, isto é, são redes de lojas que existem distribuídas por todo o país e que, aparentemente, estão atentas aos benefícios que o mobile no ponto-de-venda pode trazer para a empresa.

Vale ressaltar que, apesar das 29 empresas não aderirem ao mobile in store, elas possuem outras estratégias para facilitar o relacionamento com o cliente. Na Arezzo, Ecológica, Pandora e Polishop por exemplo, os funcionários da loja fazem uma lista de transmissão com os números de telefone dos clientes e sempre que possível enviam ofertas e descontos via WhatsApp. Já na Quem disse, Berenice, O Boticário, Marisa, Lojas Renner e Tok Stok, as campanhas promocionais geralmente são enviadas por e-mail para os clientes cadastrados no site da empresa e/ou que possuem o cartão da loja. Muitas vezes os descontos (cupons) só são validos para serem usados no Website da empresa e não é válido para todas as lojas físicas, especialmente as que são franquiadas. Depende da ação promocional.

Existem ainda algumas empresas que trabalham com descontos e ações promocionais apenas na loja física (sinalizados com placas e itens selecionados) e pouco ou nada utilizam o que a tecnologia mobile in store poderia oferecer. Esse é o caso da Kalunga. Por fim, ficou evidenciado que as lojas The Body Shop, Morana e Kopenhagen publicam ofertas exclusivas pelo Instagram da empresa para os seguidores das redes sociais.

\section{Canais de venda}

Na busca constante pela satisfação do cliente, as empresas têm aprimorado suas formas de levar os produtos até eles, disponibilizando meios ainda mais práticos e acessíveis para que o consumidor possa fechar a compra. Os canais de venda são pontos fortes no processo de criação de valor para a marca e diferenciação em meio aos concorrentes.

Segundo Coy (2013), os dispositivos tecnológicos estão mudando o comportamento de compra do 
consumidor e as empresas desfrutam desse cenário para anunciar ofertas especiais instantâneas pelo celular, possibilitar o resgate de uma promoção apresentando um código na tela do celular, transmitir mais informações sobre um produto ou dar a chance dos clientes compararem preços de lojas próximas usando aplicativos.

Os novos consumidores têm acesso a toda e qualquer informação de forma rápida e eficiente e um número enorme de possibilidades de compra na internet. $\mathrm{O}$ uso de tecnologias associadas a plataformas móveis tem estimulado o consumidor a pesquisar, comparar, experimentar e até personalizar produtos e serviços enquanto estão dentro de lojas físicas.

As novas gerações querem participar da construção do produto e serem capazes de compartilhar suas experiências, e, para entregar esse valor aos consumidores, as empresas estão se movimentando no sentido de oferecer mais dados e tecnologias nas lojas (JARA et al., 2012). Com isso, se faz necessário que as empresas estejam atentas às constantes mudanças e atualizações em seus canais de venda, tendo em vista que o mesmo deve estar sempre acessível e disponível aos consumidores - que buscam cada vez mais facilidade e tecnologia na tomada de decisão.

A partir dos dados obtidos na pesquisa, o quadro abaixo apresenta questões relevantes no que diz respeito às estratégias das empresas com relação aos seus canais de venda. Fazendo uma análise geral, é possível identificar que boa parte das organizações estudadas utilizam apenas o site na internet como forma de canal de venda.

Quadro 7: Canais de venda.

\begin{tabular}{|c|c|c|c|c|}
\hline Empresa & $\begin{array}{l}\text { Venda online } \\
\text { dentro da loja } \\
\text { física }\end{array}$ & $\begin{array}{c}\text { Checkout no PDV, para } \\
\text { encomendar a peça e receber } \\
\text { em casa }\end{array}$ & $\begin{array}{c}\text { Encomendar e pagar um produto } \\
\text { no PDV sem passar pelo caixa } \\
\text { humano }\end{array}$ & $\begin{array}{c}\text { Utilização } \\
\text { de site }\end{array}$ \\
\hline Adidas & Não & Não & Não & Sim \\
\hline Alecrim & Não & Não & Sim & Não \\
\hline Arezzo & Não & Não & Não & Sim \\
\hline Camicado & Não & Não & Não & Sim \\
\hline C\&A & Sim & Não & Sim & Sim \\
\hline Centauro & Sim & Sim & Não & Sim \\
\hline Chilli Beans & Não & Não & Não & Sim \\
\hline $\begin{array}{l}\text { Chocolates } \\
\text { Brasil Cacau }\end{array}$ & Não & Não & Não & Sim \\
\hline Delta Expresso & Não & Não & Não & Sim \\
\hline Ecológica & Não & Não & Não & Sim \\
\hline Farm & Sim & Não & Não & Sim \\
\hline Kalunga & Não & Não & Não & Sim \\
\hline Kopenhagen & Não & Não & Não & Sim \\
\hline Le Biscuit & Não & Não & Não & Sim \\
\hline Livraria Leitura & Não & Não & Não & Sim \\
\hline $\begin{array}{c}\text { Lojas } \\
\text { Americanas }\end{array}$ & Sim & Sim & Não & Sim \\
\hline Magazine Luíza & Sim & Não & Não & Sim \\
\hline Marisa & Não & Não & Não & Sim \\
\hline Morana & Não & Não & Não & Sim \\
\hline Nagem & Não & Não & Não & Sim \\
\hline Narciso & Não & Não & Não & Sim \\
\hline O Boticário & Não & Não & Não & Sim \\
\hline Pandora & Sim & Não & Não & Sim \\
\hline Polishop & Sim & Não & Não & Sim \\
\hline $\begin{array}{l}\text { Quem disse, } \\
\text { Berenice? }\end{array}$ & Não & Não & Não & Sim \\
\hline
\end{tabular}




\begin{tabular}{|c|c|c|c|c|}
\hline Renner & Sim & Não & Não & Sim \\
\hline Riachuelo & Não & Não & Não & Sim \\
\hline Ri Happy & Não & Não & Não & Sim \\
\hline Saraiva & Sim & Não & Não & Sim \\
\hline Tok Stok & Sim & Não & Não & Sim \\
\hline The Body Shop & Não & Sim & Não & Sim \\
\hline Vivara & Sim & &
\end{tabular}

Diante da observação do quadro, foi perceptível que apesar da teoria ressaltar a importância de investimentos - principalmente tecnológicos - nos canais de venda, as empresas ainda estão muito abaixo do esperado, tendo em vista que grande parte delas não possui as técnicas que foram exemplificadas na pesquisa em questão.

Quando nos referimos à venda online dentro da loja física, com a possiblidade de fazer a compra pelo celular e retirar o produto na loja, apenas 11 lojas das 32 que foram pesquisas relataram utilizar essa tecnologia. Vale ressaltar que mesmo as lojas que utilizam essa técnica, possuem pouca informação sobre tal. Muitos atendentes também se mostraram desmotivados com o fato de usar o celular para efetuar a compra dentro da loja física, tendo em vista que deixariam de ganhar comissão pela venda realizada.

Outro ponto que deve ser levado em consideração é o fato de grande parte das lojas que responderam positivamente à pergunta, indagarem em seguida que não são todos os produtos da loja física que estão disponíveis para compra online. Com isso, é possível perceber que essa técnica ainda se mostra incipiente e pouco utilizada nas empresas estudadas.

Ao serem indagados sobre um sistema de checkout na saída do provador, que possibilita encomendar a peça certa, receber o pagamento e entregá-la na casa do cliente, obtivemos um resultado positivo de apenas 04 lojas que utilizam esta técnica. A Centauro, Americanas, Tok Stok e Vivara foram as únicas a implementar um sistema de checkout e encomenda - caso a peça desejada não seja encontrada na loja física - com a possibilidade de receber o produto em casa. Dentre as empresas indagadas, a Vivara ainda acrescentou que em seu sistema não há entrega de produtos, o pedido deve ser retirado na loja quando estiver disponível.

A falta de informação também foi notória ao questionarmos os atendentes sobre a possibilidade de pagar algum produto dentro da loja física sem passar pelo caixa humano. Dentre as 32 lojas, apenas 2 utilizam essa técnica, a Alecrim e a C\&A. No entanto, o atendente da Alecrim não conseguiu executar esta tecnologia. O mesmo afirmou que já presenciou consumidores realizando o pagamento desta forma. Todavia, o rapaz não soube utilizá-la e nem se mostrou seguro ao passar informações sobre ela.

Com o decorrer da pesquisa e das questões relacionadas aos canais de venda, identificamos que grande parte das empresas o enxergam de forma simples, onde não requer alto investimento e preocupação. Muitos entendem 'canais de venda' apenas como sites para comercializar seus produtos. No entanto, este item ainda tem muito a ser explorado e implementado de diversas formas nas organizações.

Dentre as lojas que realizamos a pesquisa, apenas uma (Alecrim) não possui site para divulgação de produtos, todas as demais possuem. Entretanto, sabemos que apenas a ferramenta de site na internet não é suficiente para trazer melhorias significativas e constantes aos canais de vendas de uma empresa. 
Tendo em vista que as tecnologias digitais se entrelaçaram no tecido da vida cotidiana até se tornarem indistinguíveis (WEISER, 1991), onde nota-se que a geração atual de usuários utiliza a internet de maneira praticamente imperceptível, é preciso que as organizações estejam atentas à implementação dessas ferramentas como forma de crescimento e elevação da satisfação dos clientes.

\section{CONCLUSÕES}

A presente pesquisa teve como objetivo investigar como se dá a experiência mobile in store em lojas de um shopping center, para tanto, utilizou-se um roteiro estruturado de observação participante que resultou em dados confrontados coma teoria para que se chegasse às seguintes conclusões: No quesito uso de tecnologias mobile, a adoção de ferramentas no PDV ainda é incipiente. As empresas pesquisadas limitamse à disponibilização de informações sobre os produtos através de seus sites ou redes sociais, sejam características dos bens ou o preço para eventuais comparações. Quanto ao uso de tecnologias mobile, o QRCode só foi identificado em três empresas, todas elas de grande porte; realidade aumentada e sistemas de self-checkout não estão presentes em nenhuma das lojas pesquisadas. A ferramenta mobile que vem sendo cada vez mais empregada pelas empresas no PDV é a do M-Payment, que possibilita o pagamento via cartão online. Pode-se afirmar, entretanto, que esta não é uma ação idealizada inteiramente pelas empresas, mas facilitada pelos bancos que estão buscando cada vez mais soluções para aumentar a segurança de seus clientes.

Diante o exposto, podemos concluir que apenas as lojas C\&A, Centauro e Lojas Americanas representando $10 \%$ das empresas estudadas -, desenvolvem ações estratégicas que relacionam a tecnologia mobile e o relacionamento com o cliente no ponto-de-venda. Todas elas são consideradas de grande porte e acreditam que é no ponto-de-venda que as ações de marketing devem ser desenvolvidas para promover o consumo e tornar a tomada de decisão do consumidor mais rápida e assertiva. No que concerne à capacitação dos colaboradores, foi possível concluir que ela acompanha o pouco ou nenhum uso de tecnologias móveis. A maior parte deles não é capacitada para instruir as pessoas sobre vendas online, mesmo diante de informações mais básicas como o acesso ao site ou aplicativo.

Semelhante à capacitação dos colaboradores, o ambiente de loja também é negligenciado no que diz respeito às tecnologias móveis. A grande maioria das empresas não dispõe sequer de wi-fi, o que impossibilita qualquer ação de vendas ou aplicação de tecnologias online no ambiente. Considera-se, portanto, que as organizações poderiam atentar para a melhoria do ambiente físico, adaptando-o e adotando tecnologias inovadoras que podem fazer significativa diferença no alcance dos seus objetivos.

Quando se trata de canais de venda das empresas estudadas, a pesquisa nos mostra que a tecnologia neste quesito ainda é utilizada de modo incipiente, sendo basicamente explorada em forma de sites na internet que divulgam e vendem os produtos. Com isso, nota-se que ainda há muito a ser implementado para levar maior comodidade e praticidade aos consumidores e aumentar o leque de possibilidades das empresas em satisfazer os seus clientes. Deve-se estar sempre atento às formas de inovação e ofertas de praticidade ao consumidor, pois os canais de venda são pontos fortes no processo de criação de valor para a marca e 
diferenciação em meio aos concorrentes.

De maneira geral, a presença de tecnologias móveis foi pouco notada, de modo que todos os fatores analisados acompanham a não adoção por parte da maioria das organizações. Tal fato pode ser explicado, entre outros fatores, por uma questão regional, visto que em algumas empresas que são franquias, a tecnologia é adotada em outras localidades e na cidade de João Pessoa não.

Como limitações, essa pesquisa apresenta a ausência de literatura científica sobre a temática, considerando que o roteiro foi criado com base na literatura disponível. Como o assunto é novo, não há construtos validados na literatura que pudessem ser utilizados para auxiliar na construção do roteiro de observação sobre o mobile in store. Como recomendação de futuros trabalhos, indicamos que sejam feitas pesquisas junto aos consumidores com o objetivo de identificar como ocorre a sua experiência em loja, além de estudos com a aplicação de entrevistas em profundidade com gestores e/ou funcionários das empresas.

\section{REFERÊNCIAS}

ABRAHÃO, R. S.; MORIGUCHI, S. N.; ANDRADE, D. F.. Intention of adoption of mobile payment: An analysis in the light of the Unified Theory of Acceptance and Use of Technology (UTAUT). Revista de Administração e Inovação, v.13, p.221-230, 2016.

BAKARE, B. I.; EEBA, W. M.. A Comprehensive Review of Wireless Fidelity (Wi-Fi) Technology In Nigeria. 2018.

BAKER, J.; PARASURAMAN, A.; GREWAL, D.; VOSS, G. B.. The influence of multiple store environment cues on perceived merchandise value and patronage intentions. Journal of Marketing, v.66, p.120-141, 2002.

BARDIN, L.. Análise de conteúdo. Lisboa: Edições 70, 2007.

BITNER, M. J.. Servicescapes: The impact of physical surroundings on customers and employees. Journal of marketing, v.56, n.2, p.57-71, 1992.

BLESSA, R.. Merchandising no Ponto de venda. 5 ed. São Paulo: Atlas. 2010.

BLESSA, R.. Merchandising no ponto-de-venda. 4 ed. São Paulo: Atlas, 2007.

BOTELHO, D.; GUISSONI, L.. Varejo: competitividade e inovação. Revista de Administração de Empresas, v.56, n.6, p.596-599, 2016.

CARVALHO, M. G.. Tecnologia, Desenvolvimento Social e Educação Tecnológica. Revista Educação \& Tecnologia, Curitiba, p.70-87, 1997.

CASTELLS, M.. A sociedade em rede. 6 ed. São Paulo: Paz e Terra, 1999.

CATA, T.; PATEL, P. S.; SAKAGUCHI, T.. QR Code: A New Opportunity for Effective Mobile Marketing. IBIMA Publishing Journal of Mobile Technologies, Knowledge and Society, 2013.

CLIQUET, G.; PICOT-COUPEY, K.; HURÉ, E.; GAHINET, M.C.. Shopping with a smart- phone- a French-Japanese perspective. Marketing ZFP, v.36, n.2, p.96-106, 2014. DOI: https://doi.org/10.15358/0344-1369 2014 296

COY, D. R.. How Technology and mobile devices are changing the way we shop. 2013.

DAHLBERG, T.; MALLAT, N.; ONDRUS, J.; ZMIJEWSKA, A.. Past, present and future of mobile payments research: $A$ literature review. Electronic Commerce Research and Applications, v.7, p.165-181, 2008.

DONOVAN, R.; ROSSITER, J.. Store Atmosphere: An Environmental Psychology Approach. Journal of Retailing, v.58, p.34-57, 1982.

FREITAS, A. P. R. R. P.. QR code: tendência de evolução comercial no ponto-de-venda físico de retalho. Tese (Doutorado) - Universidade Europeia, Lisboa, 2018.

FRIDMAN, L. C.. Vertigens pós-modernas: configurações institucionais contemporâneas. Rio de Janeiro: Relume Dumará, 2000.

GODOY, B.. Descubra como as etiquetas RFID podem otimizar a logística da sua empresa, 2018.

GOMIDE, T. L. F.; BRAGA, A. G. M.. A externalidade positiva na avaliação de âncora em shopping center. 2007.

HUI, S. K.; INMAN, J. J.; HUANG, Y.; SUHER, J.. The Effect of In-Store Travel Distance on Unplanned Spending: Applications to Mobile Promotion Strategies. Journal of Marketing, v.1, n.77, p.1-16, 2013.

IBGE. Instituto Brasileiro de Geografia e Estatística. $69 \%$ dos brasileiros já têm acesso à internet pelo celular, afirma IBGE. Rio de Janeiro: IBGE, 2018.

IBGE. Instituto Brasileiro de Geografia e Estatística. Pesquisa do IBGE revela que $\mathbf{1 3 8}$ milhões de brasileiros possuem um smartphone. Rio de Janeiro: IBGE, 2018. 
JARA, A. J.; PARRA, M. C.; SKARMETA, A. F.. Marketing 4.0: A New Value Added to the Marketing through the Internet of Things. 2012.

JARABA, F. B.; GARRIDO, P. C.; GARCÍA, G. C.; RUIZ, I. L.; GÓMEZ-NIETO, M. Á. G. N.. A Ubiquitous NFC Solution for the Development of Tailored Marketing Strategies Based on Discount Vouchers and Loyalty Cards. 2013.

KARNOUSKOS, S.; FOKUS, F.. Mobile payment: A journey through existingprocedures and standardization initiatives. IEEE Communications Survey. The Electronic Magazine of Original Peer-Reviewed Survey Articles, fourthquarter, v.6, n.4, p.44-66, 2004.

KOTLER, P.. Marketing 4.0. Rio de Janeiro: Sextante, 2017.

KOUROUTHANASSIS, P. E.; GIAGLIS, G. M.. Introduction to the special issue mobile commerce: the past, present, and future of mobile commerce research. International Journal of Electronic Commerce, v.16, n.4, p.5-18, 2012.

KOWATSCH, T.; MAASS, W.. In-store consumer behavior: How mobile recommendation agents influence usage intentions, product purchases, and store preferences. Computers in Human Behavior, v.26, n.4, p.697-704, 2010.

KROSCHKE, M.; STEINER, M.; STAFFLAGE, M.; KRAFFT, M.. How mobile in-store advertising influences purchase intention: Value drivers and mediating effects from a consumer perspective. Psychology \& Marketing, v.34, n.2, p.157-174, 2017.

KUMAR, K.. Da sociedade pós-industrial à pós-moderna: novas teorias sobre o mundo contemporâneo. Rio de Janeiro: Jorge Zahar, 1997.

LIMA, C. A. R.; CALAZANS, J. H. C.. Pegadas digitais: "big data" e informação estratégica sobre o consumidor. In: SIMPÓSIO EM TECNOLOGIAS DIGITAIS E SOCIABILIDADE. Anais. Salvador, 2013.

MALLAT, N.. Exploring consumer adoption of mobile Payments - a qualitative study. Journal of Strategic Information Systems, v.16, p.413-432, 2007.

MERRIAM, S.. Qualitative research: A guide to design and implementation. São Francisco: Jossey-Bass, 2009.

MMA. Mobile Marketing Association. Updates Definition of Mobile Marketing. MMA, 2009.

NIELSEN, J.. Risks of quantitative studies. 2004.

PEDROSO, R. M. M.. A Propensão dos Consumidores para a Adoção de Tecnologias Self-service. O caso do Self-checkout no Retalho. Tese (Mestrado) - Faculdade de Economia da Universidade do Porto, Porto, 2013.
PNAD. Pesquisa Nacional por Amostra de Domicílios. Número de brasileiros com celular cresceu mais de $131 \%$ em oito anos. Rio de Janeiro: PNDA, 2013.

PORTER, M. E.; HEPPELMANN, J. E.. A Manager's Guide to Augmented Reality. Harvard Bisiness Review, 2017.

POUSTTCHI, K.. Handbook of Research on Mobile Marketing Management. 2009.

RAO, S.; TROSHANI, I. A.. Conceptual framework and propositions for the acceptance of mobile services. Journal of Theoretical and Applied Electronic Commerce Research, v.2, n.2, p.61-73, 2007.

RIBEIRO, M. W. S.; ZORZAL, E. R.. Realidade Virtual e Aumentada: Aplicações e Tendências. In: SYMPOSIUM ON VIRTUAL AND AUGMENTED REALITY, 13. Anais. Uberlândia: SBC, 2011.

SAB, G. A. A.; FERREIRA, R. C.; ROZENDO, R. G.. Near Field Communication. 2013.

SCHETZ, D.. Comunicação no ponto de venda: um diferencial competitivo de marca. 2012.

SHANKAR, V.; KLEIJNEN, M.; RAMANATHAN, S.; RIZLEY, R.; HOLLAND, S.; MORRISSEY, S.. Mobile shopper marketing: Key issues, current insights, and future research avenues. Journal of Interactive Marketing, v.34, p.37-48, 2016.

SHANKAR, V.; VENKATESH, A.; HOFACKER, C.; NAIK, P.. Mobile marketing in the retailing environment: current insights and future research avenues. Journal of interactive marketing, v.24, n.2, p.111-120, 2010.

SOUZA, V. M.; SOUZA, V. M.. As inovações tecnológicas e os efeitos sobre a produção e o consumo. Salvador: UESB, 2014.

STRUNCK, G.. Branding no varejo: Popai: the global association for marketing at retail: Brasil. 2012.

TERBLANCHE, N. S.; BOSHOFF, C.. The relationship between a satisfactory in-store shopping experience and retailer loyalty. South African. Journal of Business Management, v.37, n.2, p.33-43, 2006.

UNDERHILL, P.. Vamos às compras: a ciência do consumo. Rio de Janeiro: Elsevier, 1999.

VAN DER HEIJDEN, H.. Mobile decision support for in-store purchase decisions. Decision Support Systems, v.42, n.2, p.656-663, 2006.

WEISER, M.. The computer for the 21st century. Scientific American, v.265, n.3, p.66-75, 1991.

ZHANG, R.; CHEN, J. Q.; LEE, J. C.. Mobile Commerce and Consumer Privacy Concerns. Journal of Computer Information Systems, v.53, n.4, p.31-38, 2015.

A CBPC - Companhia Brasileira de Produção Científica (CNPJ: 11.221.422/0001-03) detém os direitos materiais desta publicação. Os direitos referem-se à publicação do trabalho em qualquer parte do mundo, incluindo os direitos às renovações, expansões e disseminações da contribuiç̃o, bem como outros direitos subsidiários. Todos os trabalhos publicados eletronicamente poderão posteriormente ser publicados em coletâneas impressas sob coordenação da Sustenere Publishing, da Companhia Brasileira de Produção Científica e seus parceiros autorizados. Os (as) autores (as) preservam os direitos autorais, mas não têm permissão para a publicação da contribuição em outro meio, impresso ou digital, em português ou em tradução. 